\title{
Gender Dimorphism of Permanent Maxillary First Molar - A Forensic Radiographic Study
}

\author{
Dr.Anu Babu ${ }^{1}$, Dr. Laxmikanth Chatra ${ }^{2}$ \\ ${ }^{1}$ (Department of Oral Medicine and Radiology, Yenepoya Dental College, India) \\ ${ }^{2}$ (Department of Oral Medicine and Radiology, Yenepoya Dental College, India)
}

\begin{abstract}
:
Aims and objectives: Identification of an individual is based on characteristics like gender, age and racial background unique to that individual. Out of all the parameters determination of gender falls first in line. Teeth can be used to determine gender dimorphism as they are the hardest structures and can withstand any adverse conditions. The present study aims to determine gender of an individual based on the mesio-distal (MD) dimensions of permanent maxillary first molar teeth from a panoramic radiograph and analyse sexual dimorphism exhibited by the tooth.

Materials And Methods:MD width of 100 permanent maxillary first molar teeth were measured from panoramic radiograph of 50 male and 50 female patients between the age group of 18-40 years. Statistical analysis was performed using SPSS 22.

Results: Results showed no statistical significance in the MD width of permanent maxillary first molar between males and females. In conclusion MD width of maxillary molars measured from panoramic radiograph have been found not to demonstrate significant sexual dimorphism.

Keywords - Identification, Gender Dimorphism, Panoramic Radiograph, Mesio-distal Width, Maxillary Molar
\end{abstract}

\section{Introduction}

Identification of an individual from the collected evidence and human remains is one of the greatest challenges which humans have confronted [1]. Identification is based on characteristics unique to the individual [2]. Identification of individual is of paramount importance in mass disasters like earthquakes, Tsunamis, in crime investigations, in ethnic studies, and in identification of mutilated and decomposed bodies like victims of motor vehicle accidents, drowned persons, and victims of fire accidents [3]. Forensic anthropologists look into four parameters namely gender, age, stature and ethnicity in tentative identification of individual [4]. Out of all the parameters gender determination falls first in line [5]. This is because it reduces the number of probable matches and also methods for age and stature estimation are often gender dependent [6,7]. Among the various skeletal parts, pelvis and skull are traditional indicators of gender and the accuracy rate of determining the correct sex is as much as $100 \%$ [8].

Tooth serves as excellent evidence in forensic and anthropological studies and investigations. They are the hardest structures and their chemical composition make them more stable in the body, and are selectively preserved and fossilized. Teeth have remarkable durability as it can withstand any adverse conditions like fire, bacterial decomposition and other environmental insults. For these reasons dental structures are used as an aid in forensic studies [9].

Difference in a feature or characteristic exhibited by males and females of same species is called gender dimorphism. Many studies have shown existence of gender dimorphism in skeletal and dental characters [10]. However not as accurate as the skeletal parameters, tooth crown dimensions can be used as adjunct tool in determination of sex[11].Use of dental structures for gender determination are of paramount importance in young subjects where skeletal features have not fully developed or when skeletal fragments is recovered.

\section{Aims And Objectives}

The present study aims to determine gender of an individual based on the MD dimensions of permanent maxillary first molar teeth on panoramic radiograph and analyse gender dimorphism exhibited by the same.

\section{Materials And Methods}

The present study was conducted in the Department of Oral medicine \& Radiology, Yenepoya Dental College \& Hospital, Yenepoya University, Mangalore. A total of 100 panoramic radiographs (50 males and 50 females) that have been taken for various purposes, belonging to the age group (18 to 40 years) having the required complement of teeth (maxillary first molars with adjacent teeth) were included in the study. Patients with developmental anomalies, those undergoing orthodontic treatment and those who have undergone maxillofacial surgery were excluded. The radiographs were selected from the archives in the department. 
All the panoramic radiographs were taken using Planmeca Promax ${ }^{\circledR}$ OPG/CEPH machine that employs photostimulable phosphor plates and Agfa CR-30X ${ }^{\circledR}$ scanner under standard protocols. Panoramic radiographs taken in increased interproximal function were only included for the study. MD width of right and left maxillary $1^{\text {st }}$ molars were taken from the radiographs using Agfa NX software in centimeters $(\mathrm{cm})$. The MD width was measured from the crest of curvature on the mesial surface to the crest of curvature on the distal surface (figure $1)$.

In order to assess the reliability of the measurements, intra-observer error was tested. The same measurements were obtained from 50 randomly selected panoramic radiographs from the original sample at a different time by one person. Another observer measured the same randomly selected radiographs. Their measurements were analyzed using Student's t-test. There was no statistically significant difference between the findings of the two observers.

The data obtained were subjected to statistical analysis with the Microsoft Excel; descriptive statistics, t-tests were used to compare the dimensions measured for males and females. P-value $\leq 0.05$ was considered statistically significant.

\section{Results}

The MD width of right and left permanent maxillary first molars measured by a digital scale on panoramic radiographs and were subjected to descriptive statistics [Table 1]. It was seen that the mean values of parameters did not show statistically significant differences between males and females with $P<0.05$, in the MD dimension of permanent maxillary first molars [Table 2]

\section{Discussion}

Gender determination is considered a vital step in reconstructing the biological profile of unidentified individuals from the forensic perspective [5]. Various methods have been employed in gender determination which ranges from the simplest approaches of using bones like pelvis, skull and other methods like odontometry to the recently available techniques like DNA analysis, bone ossification tests. The newer methods provides us with promising results but are time consuming and expensive. Hence odontometry still being used as an adjunct in gender determination and can be easily applied on to a large population as it is relatively simple, less time consuming, inexpensive and reliable[12].

In the present study patients between the ages of 18 to 30 years were included and MD width of the permanent maxillary first molar were measured from panoramic radiographs using a digital scale AGFA NX software. This was in based on Doris et.al inference that early permanent dentition is best suited for odontometry because of the minimal regressive changes which can adversely affect the MD width of the tooth [13]. After applying the descriptive statistics it was found that mean MD width were slightly higher in males than in females. This is in concordance with the numerous previous studies conducted which showed mean MD width was higher in males when compared to females [2]. Studies have shown that $\mathrm{Y}$ chromosome promotes both coronal enamel and dentin growth unlike $\mathrm{X}$ chromosome were the crown growth is limited only to enamel formation. These differential effects of $\mathrm{X}$ and $\mathrm{Y}$ chromosomes on the development of tooth explains the difference in the size of tooth in males and females [14].In the present study although the mean MD width in males and females showed a very minimal difference the results were not statistically significant ( $\mathrm{P}$ value was 0.580 and 0.170 for 16 and 26 respectively).This is in contrast to the other studies were a statistically significant difference was reported.

Sonika et.al [15] conducted a study on Haryana population to assess the sexual dimorphism in permanent maxillary $1^{\text {st }}$ molars measuring the MD width on cast and clinically. Results showed sexual dimorphism amounted to $4.15 \%$ on 16 and $4.55 \%$ on 26 when measured clinically. Similar results were obtained when measured on casts. A similar study conducted by Lakhanpal et.al [16] on study models to assess the gender predictability of various maxillary tooth and concluded that the MD width of maxillary $1^{\text {st }}$ molars has the most significant value and the mean value of males were higher than females. Rashmi et.al [17] concluded that a significant difference in the mean values between males and females of Guajarati population was noted suggesting that this parameter could be used in gender assessment. The dissimilarity in the results could be explained by a variety of factors which are involved in making the measurement. Measurement of MD width from study models and those measured clinically has few limitations. The MD width is measured from the crest of curvature on the mesial surface to the crest of curvature on the distal surface. Firstly due to presence of tight contact between the teeth clinically and on a model cast placement of caliper tips becomes difficult owing to less accurate measurements. In addition anatomical location of the tooth in the dental arch is itself a challenge and chances of error is quite high. On the other hand measurements made from panoramic radiographs provides more accurate measurements from mesial contact point to distal contact point. Previous studies have proved that horizontal measurements done on digital panoramic radiographs are sufficiently accurate for clinical use [18]. 


\section{Conclusion}

The MD width of permanent maxillary first molar tooth measured from panoramic radiographs shows negligible sexual dimorphism.

\section{References}

1. Stimson PG, Mertz CA. Forensic dentistry (New York: CRC Press, 1997)1-45.

2. Eboh Deo. J. Morphol. Sci.2012;29(2): 96-100

3. Sharma P, Gupta N, Saxena S. Experimental studies of forensic odontology to aid in the identification process. Journal of Forensic Dental Sciences. 2010; 2(2):69.

4. Vij K, Text book of forensic medicine and toxicology-principles and practice $4^{\text {th }}$ edition (New Delhi: Reed Elsevier India Private Limited-A Division of Elsevier, 2008).

5. Macaluso junior, pj. Sex discrimination potential of permanent maxillary molar cusp diameters. Journal of forensic odontostomatology.2010; 28(1):22-31.

6. Scheuer L. Application of osteology to forensic medicine. Clinical Anatomy. 2002; 15(4):297-312.

7. Manchanda A, Narang R, Bhatia H, Malhotra R. Sex determination by mandibular canine index and molar odontometrics: A comparative study. Indian Journal of Oral Sciences. 2014; 5(1):16.

8. Kewal Krishan T. Personal Identification in Forensic Examinations. Anthropology. 2013; 02(01).

9. Kaushal S, Patnaik VVG, Agnihotri G. Mandibular Canine in Sex Determination. J Anat Soc India.2003; 52(2):119-24.

10. Kieser JA. Human adult odontometrics: The study of variation in adult tooth size. (Cambridge University Press,1990).

11. Sharma P, Sharma R, Singh T, Chandra P, Kumar P. Sex determination potential of permanent maxillary molar widths and cusp diameters in a North Indian population. Journal of Orthodontic Science. 2013; 2(2):55.

12. P Ahuja, A Manchanda. Application of oral hard and soft tissue structures in sex determination. The Internet Journal of Forensic Science.2009; 4 (2).

13. Ling jwong R. Tooth dimensions of Southern Chinese. HOMO - Journal of Comparative Human Biology. 2007; 58(1):67-73.

14. Iscan MY, Kedici SP. Sexual variation in bucco-lingual dimensions in Turkish dentition. Forensic Sci Int, 2003; 137: 160-4

15. Sonika V, Harshminder K, Madhushankari GS, Sri Kennath JA. Sexual dimorphism in the permanent maxillary first molar: A study of the Haryana population (India). J Forensic Odontostomatol 2011; 29:37-43.

16. Lakhanpal M, Gupta N, Rao NC, Vashisth S.Tooth Dimension Variations as a Gender Determinant in Permanent Maxillary Teeth JSM Dent .2013;1(1): 1014

17. Bhavasar R, Patel F, Soni N, Patel P, Shah V, Shah P. Evaluation of sexual dimorphism by using permanent maxillary first molar in Gujarati population. Journal of Advanced Clinical \& Research Insights. 2015; 2:16-9.

18. Schulze R, Krummenauer F, Schalldach F, d'hoedt B. Precision and accuracy of measurements in digital panoramic radiography. Dentomaxillofacial Radiology. 2000; 29(1):52-6.

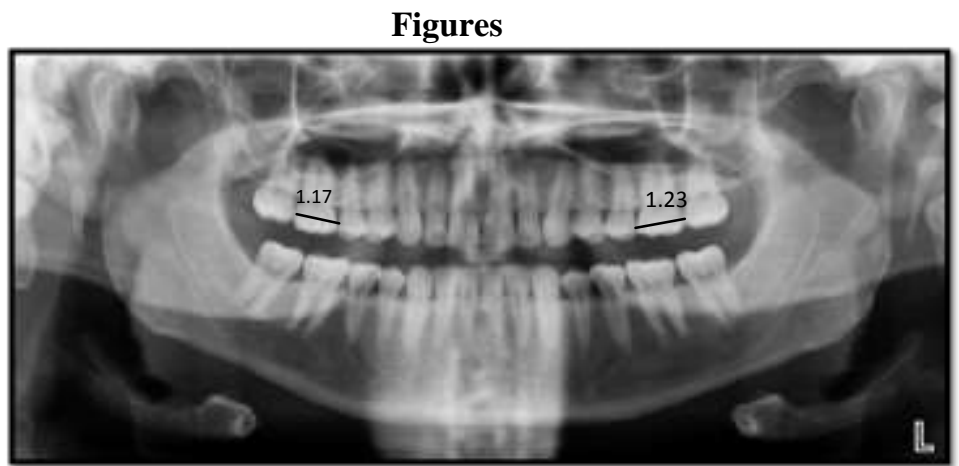

Figure 1 showing the measurement of MD width of maxillary $1^{\text {st }}$ molar on panoramic radiograph

Tables

Table 1 -Analysis of MD width of right and left maxillary $1^{\text {st }}$ molars of males and females

\begin{tabular}{|c|c|c|c|c|c|}
\hline & Sex & N & Mean & $\begin{array}{c}\text { Std. } \\
\text { Deviation }\end{array}$ & $\begin{array}{c}\text { Std. } \\
\text { Error } \\
\text { Mean }\end{array}$ \\
\hline $\begin{array}{c}\text { Mesiodistal } \\
\text { 16(Mm })\end{array}$ & Male & 50 & 12.7200 & .90509 & .12800 \\
\hline Mesiodistal & Male & 50 & 12.4480 & .83452 & .13650 \\
\cline { 2 - 6 } 26(Mm ) & Female & 50 & 12.2100 & .90108 & .11802 \\
\hline
\end{tabular}

Table 2- Evaluation of the relationship between MD width of 16, 26 with gender

\begin{tabular}{|l|c|c|c|c|c|}
\hline & T & DF & SIG. & $\begin{array}{c}\text { Mean } \\
\text { Difference }\end{array}$ & $\begin{array}{c}\text { Std. Error } \\
\text { Difference }\end{array}$ \\
\hline Mesiodistal 16(Mm ) & .556 & 98 & .580 & .10400 & .18712 \\
\hline Mesiodistal 26(Mm ) & 1.370 & 98 & .174 & .23800 & .17369 \\
\hline
\end{tabular}

